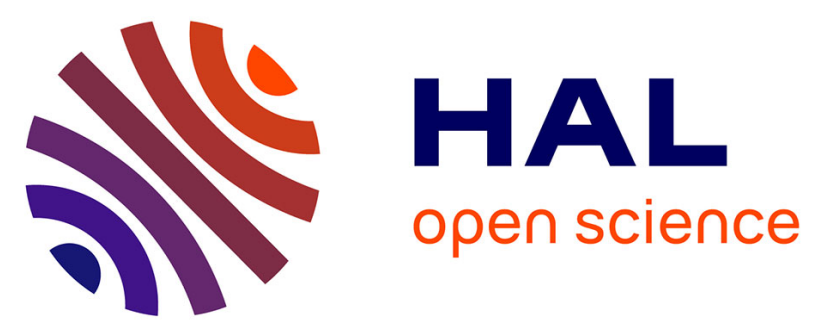

\title{
Amphiphilic core-cross-linked micelles functionalized with bis(4-methoxyphenyl)phenylphosphine as catalytic nanoreactors for biphasic hydroformylation
}

Si Chen, Andrés Fernando Cardozo Perez, Carine Julcour-Lebigue, Jean-François Blanco, Laurie Barthe, Florence Gayet, Muriel Lansalot, Franck d'Agosto, Henri Delmas, Eric Manoury, et al.

\section{To cite this version:}

Si Chen, Andrés Fernando Cardozo Perez, Carine Julcour-Lebigue, Jean-François Blanco, Laurie Barthe, et al.. Amphiphilic core-cross-linked micelles functionalized with bis(4methoxyphenyl)phenylphosphine as catalytic nanoreactors for biphasic hydroformylation. Polymer, 2015, 72, pp.327-335. 10.1016/j.polymer.2015.02.024 . hal-01877399

\author{
HAL Id: hal-01877399 \\ https://hal.science/hal-01877399
}

Submitted on 3 Mar 2021

HAL is a multi-disciplinary open access archive for the deposit and dissemination of scientific research documents, whether they are published or not. The documents may come from teaching and research institutions in France or abroad, or from public or private research centers.
L'archive ouverte pluridisciplinaire HAL, est destinée au dépôt et à la diffusion de documents scientifiques de niveau recherche, publiés ou non, émanant des établissements d'enseignement et de recherche français ou étrangers, des laboratoires publics ou privés. 


\section{Amphiphilic Core-Cross-linked Micelles Functionalized with Bis(4- methoxyphenyl)phenylphosphine as Catalytic Nanoreactors for Biphasic Hydroformylation}

Si Chen ${ }^{\mathrm{a}, \mathrm{c}}$, Andrés F. Cardozo ${ }^{\mathrm{b}, \mathrm{c}}$, Carine Julcour ${ }^{\mathrm{b}, \mathrm{c}}$, Jean-François Blanco ${ }^{\mathrm{b}, \mathrm{c}}$, Laurie Barthe $^{\mathrm{b}, \mathrm{c}}$, Florence Gayet ${ }^{\mathrm{a}, \mathrm{c}}$, Muriel Lansalot ${ }^{\mathrm{d}}$, Franck D’Agosto ${ }^{\mathrm{d}}$, Henri Delmas ${ }^{\mathrm{b}, \mathrm{c}}$, Eric Manoury ${ }^{\mathrm{a}, \mathrm{c}, *}$, Rinaldo Poli ${ }^{\mathrm{a}, \mathrm{c}, \mathrm{e}, *}$

a CNRS, LCC (Laboratoire de Chimie de Coordination), 205 route de Narbonne, BP 44099, F-31077, Toulouse Cedex 4, France, E-mail: rinaldo.poli@lcc-toulouse.fr, eric.manoury@lcc-toulouse.fr

b CNRS, LGC (Laboratoire de Génie Chimique), 4 Allée Emile Monso, BP 84234, 31030 Toulouse Cedex 4, France

c Université de Toulouse, UPS, INPT, F-31077, Toulouse Cedex 4, France

d Université de Lyon, Univ. Lyon 1, CPE Lyon, CNRS, UMR 5265, C2P2 (Chemistry, Catalysis, Polymers \& Processes), Team LCPP Bat 308F, 43 Bd du 11 Novembre 1918, 69616 Villeurbanne, France

e Institut Universitaire de France, 103, bd Saint-Michel, 75005, Paris, France

\section{Keywords:}

Reversible Addition-Fragmentation Chain Transfer (RAFT)

Polymerization-induced self-assembly (PISA)

Core-cross-linked micelle (CCM)

Catalytic nanoreactor

Biphasic hydroformylation catalysis 


\section{Abstract}

Core-cross-linked micelles (CCM) functionalized at the core with covalently linked bis $(p$ methoxyphenyl)phenylphosphine (BMOPPP) ligands have been synthesized by a three-step one-pot radical polymerization in emulsion, using the polymerization-induced self-assembly (PISA) strategy and reversible addition-fragmentation chain transfer (RAFT) as the controlling method. The CCM are obtained by chain extending in water poly(methacrylic acid-copoly(ethylene oxide) methyl ether methacrylate) (P(MAA-co-PEOMA), degree of polymerization of 30, MAA/PEOMA units molar ratio of 50:50) synthesized in a first step by RAFT with a 95:5 molar mixture of styrene and 4-[bis(p-methoxyphenyl)phosphino]styrene (BMOPPS) units. The resulting micelles exhibiting a core composed of $\mathrm{P}(\mathrm{S}$-co-BMOPPS $)$ segments with a degree of polymerization of 300 are then crosslinked in a third step with a mixture of di(ethylene glycol) dimethacrylate (DEGDMA) and styrene. The resulting BMOPPP@CCM exhibit a narrow size distribution $(\mathrm{PDI}=0.16)$ with an average diameter of $81 \mathrm{~nm}$ in water and swell in THF or by addition of toluene to the latex. The addition of $\left[\mathrm{Rh}(\mathrm{acac})(\mathrm{CO})_{2}\right]$ to the toluene-swollen latex results in metal coordination to the phosphine ligands. ${ }^{31} \mathrm{P}\left\{{ }^{1} \mathrm{H}\right\}$ NMR spectroscopy shows that the Rh centers undergo rapid intraparticle phosphine ligand exchange. Application of these nanoreactors to the aqueous biphasic hydroformylation of 1-octene shows excellent activity and moderate catalyst leaching.

\section{Introduction}

The power of controlled radical polymerization and the wide choice of monomers and polymerization mechanisms have made it possible to design and synthesize quite complex functionalized macromolecular architectures that were unimaginable only 20 years ago [1]. Among many possible uses of functional polymers, the area of nanoreactors for catalytic applications has developed rather recently but is now rapidly expanding [2-4]. By careful design, it is now possible to generate macromolecular architectures where the catalyst is confined in a specific part of the macromolecule conferring specific properties to the catalyst environment (affinity for the reaction substrate, size selectivity, site confinement, etc.) while other parts of the macromolecule are responsible for the nanoreactor compatibility with its 
environment (homogeneous dispersion, response to stimuli such as heat, $\mathrm{pH}$, magnetic fields etc.). As notable examples, Fréchet et al. have shown the principle of catalyst site confinement for a cascade organic transformation involving one acid-catalyzed and one base-catalyzed step [5], O'Reilly et al. have turned self-assembled catalytic micelles into unimolecular polymer particles by shell-cross-linking [6], Sawamoto et al. have built thermoresponsive phosphinecontaining microgels and applied them to a few transformations under aqueous biphasic conditions [7, 8], and Resmini et al. have used the principle of molecular imprinting to develop shape-selective catalytic nanogels $[9,10]$. In most cases, the developed nanoreactors were applied to catalytic transformations under homogeneous conditions. Occasionally, the catalyst was recovered and recycled by ultrafiltration, by precipitation, or by thermoregulation.

Efficient catalyst recovery and recycling is of great interest in industrial homogeneous catalysis, particularly when using expensive metals and/or ligand systems, the aqueous biphasic approach being the most attractive one because of the simplicity of the necessary equipment and operating procedures [11]. The prime example of successful industrial application is the Rhone-Poulenc/Ruhrchemie hydroformylation of propene [12], where the $\mathrm{Rh}$ catalyst is completely confined in the aqueous phase by triphenylphosphine trisulfonate (TPPTS), but this process is unfortunately inefficient for the higher olefins because of their insufficient water solubility. Among the investigated strategies for circumventing this problem, micellar catalysis is the most attractive one.

Core-functionalized micelles, resulting from the self-assembly of surfactants or amphiphilic diblock copolymers where the catalyst is anchored to the hydrophobic part, are the simplest possible type of nanoreactor and many applications of biphasic catalysis have been described [13-18]. The dynamic nature of micelles, however, results in two major obstacles to large scale industrial implementation: uncontrolled swelling leading to the formation of stable emulsions and loss of the free surfactants, even when the critical micelle concentration (CMC) is very low [19-24]. For instance, anchoring of a rhodium complex to a poly(norbornene)-based amphiphilic diblock copolymer with $\mathrm{CMC}=2.2 \cdot 10^{-6} \mathrm{M}$ and application to the aqueous biphasic 1-octene hydroformylation led to excellent turn over frequency (TOF) but also to leaching with $9 \mathrm{ppm}$ of $\mathrm{Rh}$ detected in the organic product phase [25], which is an intolerably high loss for large scale production.

In order to remove both problems, we have recently introduced a new approach, which consists of cross-linking amphiphilic block copolymer micelles at the core to generate unimolecular nano-objects [26, 27]. These core-cross-linked micelles (CCM) have been assembled by an efficient one-pot procedure by a polymerization-induced self-assembly (PISA) 
in water [28, 29], using reversible addition-fragmentation chain transfer (RAFT) polymerization in a convergent approach. The ligand needed to bind the catalytic metal was incorporated statistically as a phosphine functionalized comonomer, 4-diphenylphosphinostyrene (DPPS), at low loading (5-25\% molar) in the hydrophobic core. This monomer carries a triphenylphosphine (TPP) ligand for metal coordination. The resulting TPP@CCM latex could readily be charged with the hydroformylation precatalyst, $\left[\mathrm{Rh}(\mathrm{acac})(\mathrm{CO})_{2}\right]$, and the resulting catalytic nanoreactors, $[\mathrm{Rh}(\mathrm{acac})(\mathrm{CO})(\mathrm{TPP})] @ \mathrm{CCM}$, were successfully used in the aqueous biphasic hydroformylation of 1-octene with excellent activity, catalyst recyclability, and low metal leaching (down to $1.8 \mathrm{ppm}$ ) [26].

On the basis of this initial success, we have embarked in a more systematic study of the CCM approach to aqueous biphasic catalysis. Initial questions concerned the modification of the CCM structure in terms of catalyst density and size of the hydrophobic core and the hydrophilic shell (degree of polymerization) and how such changes affect the catalytic performance [27]. Another point of interest is access to CCMs with other ligand functionalities in the hydrophobic core for wider applications in catalysis. In this contribution, we report the synthesis of a CCM functionalized with the bis(4-methoxyphenyl)phenylphosphine (BMOPPP) ligand, BMOPPP@CCM, its physical characterization, its coordination chemistry with $\left[\mathrm{Rh}(\mathrm{acac})(\mathrm{CO})_{2}\right]$, and the application of the $\left[\mathrm{Rh}(\mathrm{acac})(\mathrm{CO})_{2}\right]$-loaded nanoreactors, [Rh(acac)(CO)(BMOPPP)]@CCM, to aqueous biphasic hydroformylation. This specific ligand was chosen for the first CCM chemical modification because of its structural similarity with TPP and consequently of the expected similar polymerization behavior, relative to DPPS, of the suitable ligand-functionalized monomer, 4-[bis(4'-methoxyphenyl)phosphino]styrene (BMOPPS). While the Rh activity in the presence of $p$-OMe-substituted arylphosphines is very similar to that in the presence of the unsubstituted analogues for hydroformylations conducted with soluble complexes under homogeneous or biphasic conditions [30, 31], the $p$-OMe substitution increases the phosphine binding ability toward Rh [32]. Therefore, lower leaching may be expected if the leaching mechanism involves loss of metal from the nanoreactor core.

\section{Experimental}

\subsection{Materials}


All manipulations were performed under an inert atmosphere of dry argon by using Schlenk line techniques. 4,4'-azobis(4-cyanopentanoic acid) (ACPA, >98\%, Fluka), methacrylic acid (MAA, 99.5\%, Acros), poly(ethylene oxide) methyl ether methacrylate (PEOMA, $M_{\mathrm{n}}=950 \mathrm{~g} \mathrm{~mol}^{-1}$, Aldrich), di(ethylene glycol) dimethacrylate (DEGDMA, 95\%, Aldrich), 1,3,5-trioxane (Aldrich, > 99\%), acetylacetonatodicarbonyl rhodium(I), $\left(\left[\mathrm{Rh}(\mathrm{acac})(\mathrm{CO})_{2}\right], 99 \%\right.$ Strem), chloro(1,5-cyclooctadiene) rhodium(I) dimer $\left([\mathrm{Rh}(\mathrm{COD}) \mathrm{Cl}]_{2}\right.$, 98\%, Strem), triphenylphosphine ( $\mathrm{PPh}_{3}$ or TPP, >98.5\%, Fluka), chlorobis(4-methoxyphenyl) phosphine, (>98\%, Alfa), and 4-bromostyrene (98\%, stab. with 0.1\% 4-tert-butylcatechol, Alfa) were used as received. Styrene (S, 99\%, Acros) was purified by passing through a column of active basic aluminium oxide to remove the stabilizer. The RAFT agent 4-cyano-4thiothiopropylsulfanyl pentanoic acid (CTPPA) was synthesized as described previously [33]. Mg turnings was washed with $\mathrm{HCl}(1 \mathrm{M})$ until the metallic colour appearing then washed with diethyl ether. Solvents were dried by standard procedures and distilled under argon prior to use.

\subsection{Characterization techniques}

\subsubsection{Nuclear Magnetic Resonance}

${ }^{1} \mathrm{H}$ NMR and ${ }^{31} \mathrm{P}$ NMR spectra were recorded in $5 \mathrm{~mm}$ diameter tubes at $297 \mathrm{~K}$ in $\mathrm{D}_{2} \mathrm{O}$, DMSO- $d_{6}$ or THF- $d_{8}$ solution (the polymerization medium aliquots were directly dispersed in the solvent) using a Bruker Avance 400 spectrometer. ${ }^{1} \mathrm{H}$ and ${ }^{13} \mathrm{C}$ chemical shifts were determined using the residual peak of deuterated solvent as internal standard and are reported in ppm $(\delta)$ relative to tetramethylsilane. ${ }^{31} \mathrm{P}$ chemical shifts are reported relative to external $85 \%$ $\mathrm{H}_{3} \mathrm{PO}_{4}$. The solid-state ${ }^{13} \mathrm{C}$ NMR experiment was recorded on a Bruker Avance 400 spectrometer equipped with a $3.2 \mathrm{~mm}$ probe. The sample was spun at $16 \mathrm{kHz}$ at the magic angle using $\mathrm{ZrO}_{2}$ rotors, using a small flip angle $\left(\sim 30^{\circ}\right)$ with a recycle delay of $5 \mathrm{~s}$ and a contact time of 2 ms. Peaks are labelled as singlet (s), doublet (d), triplet (t), multiplet (m) and broad (br). The aromatic $\mathrm{C}$ positions are labeled as $C_{\mathrm{i}}$ (ipso, $\mathrm{P}$ bonded), $C_{o}$ (ortho), $C_{m}$ (meta) and $C_{p}$ (para, bonded to $\mathrm{OMe}$ or to $\mathrm{CH}=\mathrm{CH}_{2}$ ). For the $\mathrm{CCM}$ characterization, the chemical shift scale was calibrated on the basis of the solvent peak ( $\delta 2.50$ for DMSO, 3.58 and 1.73 for THF), and $1,3,5$-trioxane was used as an integration reference $(\delta 5.20)$.

\subsubsection{Size Exclusion Chromatography}

Size exclusion chromatography (SEC) measurements were performed in THF (with butylhydroxytoluene (BHT) as a flow rate marker) at $20{ }^{\circ} \mathrm{C}$ with a flow rate of $1.0 \mathrm{~mL} \mathrm{~min}{ }^{-1}$. 
All polymers were analyzed at a concentration around $5 \mathrm{mg} \mathrm{mL}^{-1}$ after filtration through a 0.45 $\mu \mathrm{m}$ pore-size membrane. The separation was carried out on a precolumn and three columns in series (type Styragel HR1 / HR3 / HR4). A multi-angle diffusion light scattering (Mini Dawn TriStar Wyatt) was used as detector coupled with a Wyatt Optilab Rex refractometer.

\subsubsection{Dynamic Light Scattering}

The intensity-average diameters of the latex particles $\left(D_{\mathrm{z}}\right)$ and the dispersity factor (PDI, polydispersity index) were measured at $25^{\circ} \mathrm{C}$ on a Malvern Zetasizer NanoZS. After filtration through a $0.45 \mu \mathrm{m}$ pore-size membrane, deionized water or THF was used to dilute the latex sample. Solutions were analyzed without further filtration to ensure that undesired populations were not removed. Data were analyzed by the general-purpose non-negative least squares (NNLS) method. The typical accuracy for these measurements was $10-15 \%$.

\subsubsection{Transmission Electron Microscopy}

The morphological analysis of the copolymer nano-objects was performed with a JEOL JEM 1011 transmission electron microscope equipped with $100 \mathrm{kV}$ voltage acceleration and tungsten filament (Service Commun de Microscopie Electronique TEMSCAN, plateforme de l'Université Paul Sabatier, Toulouse, France). Diluted latex samples were dropped on a formvar/carbon-coated copper grid and dried under vacuum.

\subsubsection{Mass Spectrometry}

The mass spectral analyses were performed with a high resolution electrospray XevoG2QT Waters instrument by "Service Commun de Spectrométrie de Masse" of the Université PaulSabatier, Toulouse, France.

\subsection{Synthesis of 4-[bis(4'-methoxyphenyl)phosphino] styrene (BMOPPS)}

Chlorobis(4-methoxyphenyl)phosphine $(1 \mathrm{~g}, 3.56 \mathrm{mmol})$ was added slowly at $0{ }^{\circ} \mathrm{C}$ to a solution of the Grignard reagent prepared from 4-bromostyrene $(0.65 \mathrm{~g}, 3.56 \mathrm{mmol})$ and $\mathrm{Mg}$ $(0.104 \mathrm{~g}, 4.275 \mathrm{mmol})$ in dry THF $(4 \mathrm{~mL})$. After the addition was complete, the reaction mixture was stirred at room temperature for $3 \mathrm{~h}$. The reaction mixture was then diluted with ethyl acetate $(30 \mathrm{~mL})$ and washed sequentially with water $(2 \times 50 \mathrm{~mL}), 10 \%$ aqueous $\mathrm{HCl}(2 \times 50 \mathrm{~mL})$, saturated aqueous $\mathrm{NaHCO}_{3}(2 \times 50 \mathrm{~mL})$, and brine $(2 \times 50 \mathrm{~mL})$. The organic layer was dried over $\mathrm{MgSO}_{4}$, filtered, and concentrated in vacuum. The crude product was purified by silica gel 
chromatography (5\% $\mathrm{Et}_{2} \mathrm{O} /$ hexane, then $\left.\mathrm{Et}_{2} \mathrm{O}\right)$ to afford 1 as a white solid $(0.66 \mathrm{~g}, 53 \%) .{ }^{1} \mathrm{H}$ NMR (400 MHz, $\left.\mathrm{CDCl}_{3}\right): \delta$ 7.39-7.22 (m, 8H, $\left.\mathrm{CH}_{\mathrm{Ar}}\right), 6.93-6.90\left(\mathrm{~m}, 4 \mathrm{H}, \mathrm{CH}_{\mathrm{Ar}}\right), 6.72(\mathrm{dd}, 1 \mathrm{H}$, $\mathrm{J}=10.9 \mathrm{~Hz}, \mathrm{~J}=17.6 \mathrm{~Hz}, \mathrm{CH}), 5.78\left(\mathrm{~d}, 1 \mathrm{H}, \mathrm{J}=17.6 \mathrm{~Hz}, \mathrm{CH}_{2}\right), 5.29\left(\mathrm{~d}, 1 \mathrm{H}, \mathrm{J}=10.9 \mathrm{~Hz}, \mathrm{CH}_{2}\right)$, 3.83 (s, 6H, CH $H_{3}$ омe). ${ }^{31} \mathrm{P}\left\{{ }^{1} \mathrm{H}\right\} \mathrm{NMR}\left(162 \mathrm{MHz}, \mathrm{CDCl}_{3}, 298 \mathrm{~K}\right): \delta-8.93 .{ }^{13} \mathrm{C}\left\{{ }^{1} \mathrm{H}\right\} \mathrm{NMR}(101.5$ $\left.\mathrm{MHz}, \mathrm{CDCl}_{3}\right): \delta 160.3\left(\mathrm{~s}, C_{p}(\mathrm{OMe})\right), 138.2\left(d, \mathrm{~J}_{\mathrm{C}-\mathrm{P}}=10.1 \mathrm{~Hz}, C_{i}, 1 \mathrm{C}\right), 137.5\left(\mathrm{~s}, 1 \mathrm{C}, C_{p} \mathrm{CHCH}_{2}\right)$, 136.5 (s, $\left.1 \mathrm{C}, C \mathrm{H}=\mathrm{CH}_{2}\right), 135.3\left(\mathrm{~d}, \mathrm{~J}=21.3 \mathrm{~Hz}, C_{\mathrm{m}}(\mathrm{OMe})\right), 133.3\left(\mathrm{~d}, \mathrm{~J}_{\mathrm{C}-\mathrm{P}}=19.3 \mathrm{~Hz}\right.$, $\left.C_{\mathrm{m}}\left(\mathrm{CHCH}_{2}\right)\right), 128.2\left(\mathrm{~d}, \mathrm{~J}_{\mathrm{C}-\mathrm{P}}=8.1 \mathrm{~Hz}, C_{i}, 2 \mathrm{C}\right), 126.2\left(\mathrm{~d}, \mathrm{~J}_{\mathrm{C}-\mathrm{P}}=6.1 \mathrm{~Hz}, C_{\mathrm{o}}\left(\mathrm{CHCH}_{2}\right)\right), 114.4(\mathrm{~s}$, $\left.\mathrm{CH}=\mathrm{CH}_{2}\right), 114.2\left(\mathrm{~d}, \mathrm{~J}=8.1 \mathrm{~Hz}, \mathrm{C}_{\mathrm{o}}(\mathrm{OMe})\right), 55.2\left(\mathrm{~s}, \mathrm{OCH}_{3}\right)$. HR EI-MS calcd for $\mathrm{C}_{22} \mathrm{H}_{21} \mathrm{O}_{2} \mathrm{P}$ 348.1356, found 348.1348. M.p.: $123{ }^{\circ} \mathrm{C}$. Elemental analysis for $\mathrm{C}_{22} \mathrm{H}_{21} \mathrm{O} 2 \mathrm{P} \cdot 0.1 \mathrm{CH}_{2} \mathrm{Cl}_{2}: \mathrm{C} \%$ 74.38, $\mathrm{H} \%$ 5.99, found $\mathrm{C} \%$ 74.57, $\mathrm{H} \%$ 5.51.

2.4. Preparation of the BMOPPP@CCM latex by one-pot RAFT polymerization in water.

\subsubsection{Step 1: Preparation of the P(MAA-co-PEOMA)-TTC macromolecular RAFT agent} (macroRAFT) in water.

A stock solution containing ACPA $\left(30 \mathrm{mg} \mathrm{mL}^{-1}\right)$ in deionized water $(1 \mathrm{~mL})$ containing also $\mathrm{NaHCO}_{3}(30 \mathrm{mg}$ ) was prepared. $100 \mu \mathrm{L}$ of this stock solution (3 mg ACPA, $0.0108 \mathrm{mmol}$ ), 15 $\mathrm{mg}$ of CTPPA $(0.054 \mathrm{mmol}), 75 \mathrm{mg}$ of MAA $(0.87 \mathrm{mmol}), 0.79 \mathrm{~g}$ of PEOMA $(0.83 \mathrm{mmol})$ and $4.2 \mathrm{~g}$ of deionized water (including the water amount of the ACPA solution) were added into a $25 \mathrm{~mL}$ flask equipped with a magnetic stirrer bar, which was then sealed with a rubber septum. 1,3,5-trioxane was also added into the flask as an internal reference for the determination of the monomer conversion by ${ }^{1} \mathrm{H}$ NMR. The solution was purged for 45 min with argon and then heated to $80{ }^{\circ} \mathrm{C}$ in a thermostated oil bath with stirring. After $120 \mathrm{~min}, 0.15 \mathrm{~mL}$ of solution was taken to determine the monomer conversion and the molar mass of the macroRAFT product. The overall monomer molar conversion was about $98 \%$ as determined by ${ }^{1} \mathrm{H}$ NMR spectroscopy in DMSO- $d_{6}$. The molar mass was analyzed by size exclusion chromatography (SEC) in THF (experimental $\left.M_{\mathrm{n}}=11200 \mathrm{~g} \mathrm{~mol}^{-1} ; Ð=1.19\right)$.

\subsubsection{Step 2: Chain extension of the macroRAFT with $S$ and BMOPPS in water.}

During Step 1, a suspension containing $1.57 \mathrm{~g}$ of $\mathrm{S}$ (15 mmol), $0.269 \mathrm{~g}$ of BMOPPS (0.772 mmol, $5 \%$ mol relative to $\mathrm{S}$ ) in $4.62 \mathrm{~g}$ of deionized water, to which was also added the ACPA stock solution ( $100 \mu \mathrm{L}$ containing $3 \mathrm{mg}$ of ACPA, $0.0108 \mathrm{mmol}$ ) were purged separately for 45 min with an argon stream at $0{ }^{\circ} \mathrm{C}$. This mixture was quickly injected into the first flask under argon at $80{ }^{\circ} \mathrm{C}$ after the end of Step 1. The separated organic/aqueous phases became one 
opaque suspension phase at around 1h. After 2 hours of further stirring for the resulting suspension, a $0.5 \mathrm{~mL}$ sample was withdrawn for analysis and the polymerization was quenched by immersion of the flask in iced water. The overall conversion of S (94\%) was determined by gravimetric analysis and that of BMOPPS (100\%) was measured by ${ }^{31} \mathrm{P}$ NMR in THF- $d_{8}$. SEC: $M_{\mathrm{n}}=43900 \mathrm{~g} \mathrm{~mol}^{-1}(\bigoplus=1.3) . D_{\mathrm{z}}(\mathrm{DLS})=78 \mathrm{~nm}(\mathrm{PDI}=0.2)$.

\subsubsection{Step 3: Cross-linking.}

In the flask containing the P(MAA-co-PEOMA)- $b$-P(S-co-BMOPPS) latex from Step 2, $0.48 \mathrm{~g}$ of $\mathrm{S}$ ( $4.6 \mathrm{mmol}), 0.137 \mathrm{~g}$ of DEGDMA $(0.565 \mathrm{mmol}, 10 \%$ mol relative to $\mathrm{S}), 90 \mu \mathrm{L}$ of the ACPA stock solution $(2.7 \mathrm{mg}$ of ACPA, $0.009 \mathrm{mmol})$ and $2.43 \mathrm{~g}$ of deionized water were further added. The mixture was purged for $1 \mathrm{~h}$ with argon at $0{ }^{\circ} \mathrm{C}$, and the flask was then placed in an oil bath thermostated at $80{ }^{\circ} \mathrm{C}$. After $90 \mathrm{~min}$, the polymerization was quenched by immersion of the flask in iced water. The overall conversion of the comonomers (97\%) was determined by ${ }^{1} \mathrm{H}$ NMR and ${ }^{31} \mathrm{P}$ NMR in THF- $d_{8}$. DLS $\left(\mathrm{H}_{2} \mathrm{O}\right): D_{\mathrm{z}}=81 \mathrm{~nm}(\mathrm{PDI}=0.16)$. DLS (THF): $\mathrm{D}_{\mathrm{z}}=207 \mathrm{~nm}(\mathrm{PDI}=0.20)$.

\subsection{Metal complexation to the phosphine ligand within the nanoparticle core.}

$\left[\mathrm{Rh}(\mathrm{acac})(\mathrm{CO})_{2}\right](31.7 \mathrm{mg}, 1.01 \mathrm{eq})$ in toluene $(1 \mathrm{~mL})$ was added to a previously swollen nanoparticles latex $\left(5 \mathrm{~mL}, 0.1 \mathrm{mg} \mathrm{mL}^{-1}\right)$ prepared from the BMOPPP@CCM latex $(2 \mathrm{~mL})$ diluted in $\mathrm{D}_{2} \mathrm{O}(3 \mathrm{~mL})$ by addition of toluene $(0.5 \mathrm{~mL})$. The swelling was very rapid $(<1 \mathrm{~min}$ upon stirring at room temperature) as confirmed by visual disappearance of the toluene phase and by the ${ }^{31} \mathrm{P}$ NMR observation of the core phosphine resonance (see Results and Discussion). The reaction mixture was stirred at room temperature for 10 min until the latex color changed to yellow. The resulting latex was washed by toluene $(2 \mathrm{x} 1 \mathrm{~mL})$ under argon to remove any excess of the $\mathrm{Rh}$ precursor; both toluene washings were colorless. The [Rh(acac)(CO)(BMOPPP)]@CCM latex was collected after decantation for further NMR studies. ${ }^{31} \mathrm{P}\left\{{ }^{1} \mathrm{H}\right\} \mathrm{NMR}\left(162 \mathrm{MHz}, \mathrm{CDCl}_{3}, 298 \mathrm{~K}\right): \delta 44.5(\mathrm{~d}, \mathrm{~J}=176 \mathrm{~Hz})$ for the polymer linked $[\mathrm{Rh}(\mathrm{acac})(\mathrm{CO})(\mathrm{BMOPPP})]$ complexes.

\subsection{Biphasic hydroformylation catalysis}

The catalytic aqueous phase was prepared under a nitrogen atmosphere by diluting the CCM latex in Milli-Q water (for a phosphine equivalent of $0.65 \mathrm{mmol}$ in $25 \mathrm{~mL}$ ), then swelling 
the hydrophobic nanoparticle core with $3 \mathrm{~mL}$ of decanal, prior to the addition of the $\mathrm{Rh}$ precursor, $\left[\mathrm{Rh}(\mathrm{acac})(\mathrm{CO})_{2}\right](43 \mathrm{mg}, 0.163 \mathrm{mmol})$, dissolved in $3 \mathrm{~mL}$ of decanal. At each step, the resulting mixture was vigorously stirred for a few minutes. This colloidal suspension was poured into the autoclave, then immediately covered by additional decanal $(56 \mathrm{~mL})$ and by 1 octene $(81.6 \mathrm{mmol})$. The reactor was flushed three times with 15 bar of nitrogen, then four times with 15 bar of syngas. It was subsequently heated under low syngas pressure ( 2 bar) and slow stirring speed (300 rpm, well below gas self-induction) to generate the catalytic species in situ, albeit hindering the start of the reaction. When the desired reaction temperature $(363 \mathrm{~K})$ was achieved (after about half an hour), stirring was stopped and the autoclave was pressurized and constantly fed with syngas at the desired pressure (20 bar). A sample was withdrawn to evaluate the amount of products formed during the heating period.

Then, the data acquisition was started and the stirring speed was set to $1200 \mathrm{rpm}$. Both temperature and pressure of the reactor and the gas ballast were recorded on-line, in order to measure the instantaneous syngas consumption. After a few hours of reaction, a final sample of the organic phase was withdrawn for the chromatographic analysis (using anisole as internal standard). Acquisition and heating were stopped and the autoclave was cooled slowly at low stirring speed (200 rpm). Once the autoclave was cold, stirring was stopped and the reactor was depressurized and purged four times with nitrogen. The whole reaction mixture was left to settle overnight under a nitrogen atmosphere. Finally, the contents of the autoclave were then taken out and separated. An aliquot of the recovered organic phase was diluted into water (with a volumetric dilution factor of $10^{5}$ ) for the Rh ICP/MS analysis.

\section{Results and Discussion}

\subsection{Monomer and copolymer synthesis}

The BMOPPP@CCM latex was prepared by an analogous procedure to that recently described for the similar TPP@CCM latex [26], by replacing the DPPS comonomer with the related 4-[bis(4'-methyoxyphenyl)phosphine]styrene (BMOPPS). This new ligand-functionalized monomer was prepared from chlorobis(4-methoxyphenyl)phosphine and 4-bromostyrene following the same procedure reported for the synthesis of DPPS (see Scheme 1) [34]. The spectroscopic properties are entirely as expected, with the ${ }^{31} \mathrm{P}\left\{{ }^{1} \mathrm{H}\right\}$ NMR resonance $(\delta-8.93$ in $\mathrm{CDCl}_{3}$ ) only slightly upfield shifted from that of DPPS, the protons of the vinyl group yielding 
a characteristic pattern in the 6.7-5.3 region of the ${ }^{1} \mathrm{H}-\mathrm{NMR}$ spectrum, and the corresponding $\mathrm{C}$ nuclei yielding resonances at $\delta 136.5$ and 114.4 in the ${ }^{13} \mathrm{C}\left\{{ }^{1} \mathrm{H}\right\}$ NMR spectrum, which is shown in full in the SI (Figure S1).

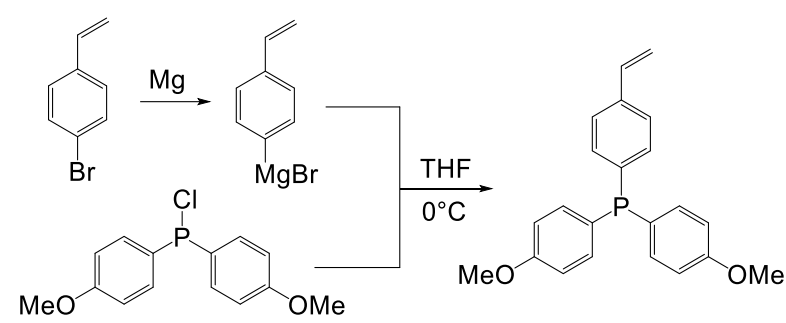

Scheme 1. Procedure used for the synthesis of BMOPPS.

The BMOPPP@CCM latex was obtained by a one-pot three-step synthesis, based on the RAFT methodology, as described in Scheme 2. The kinetics of each step is illustrated in Figure 1. In the first step, a 50:50 mixture of methacrylic acid (MAA) and poly(ethylene oxide) methyl ether methacrylate (PEOMA) with an average of 19 ethylene oxide units was statistically copolymerized using 4-cyano-4-thiothiopropylsulfanyl pentanoic acid (CTPPA) as the controlling agent and 4,4'-azobis(4-cyanopentanoic acid) (ACPA) as the radical source. Full conversion was attained within $2 \mathrm{~h}$ (see Figure 1, left). The overall monomer/controlling agent ratio being set at 30 , the polymer chains obtained at complete conversion have an experimentally determined (SEC analysis) number average molar mass, $M_{\mathrm{n}}=11200 \mathrm{~g} \mathrm{~mol}^{-1}$, not far from the expected 30 monomer units per chain $\left(M_{\mathrm{n}, \mathrm{th}}=15625 \mathrm{~g} \mathrm{~mol}^{-1}\right)$ and a low dispersity $(\bigoplus=1.19)$.

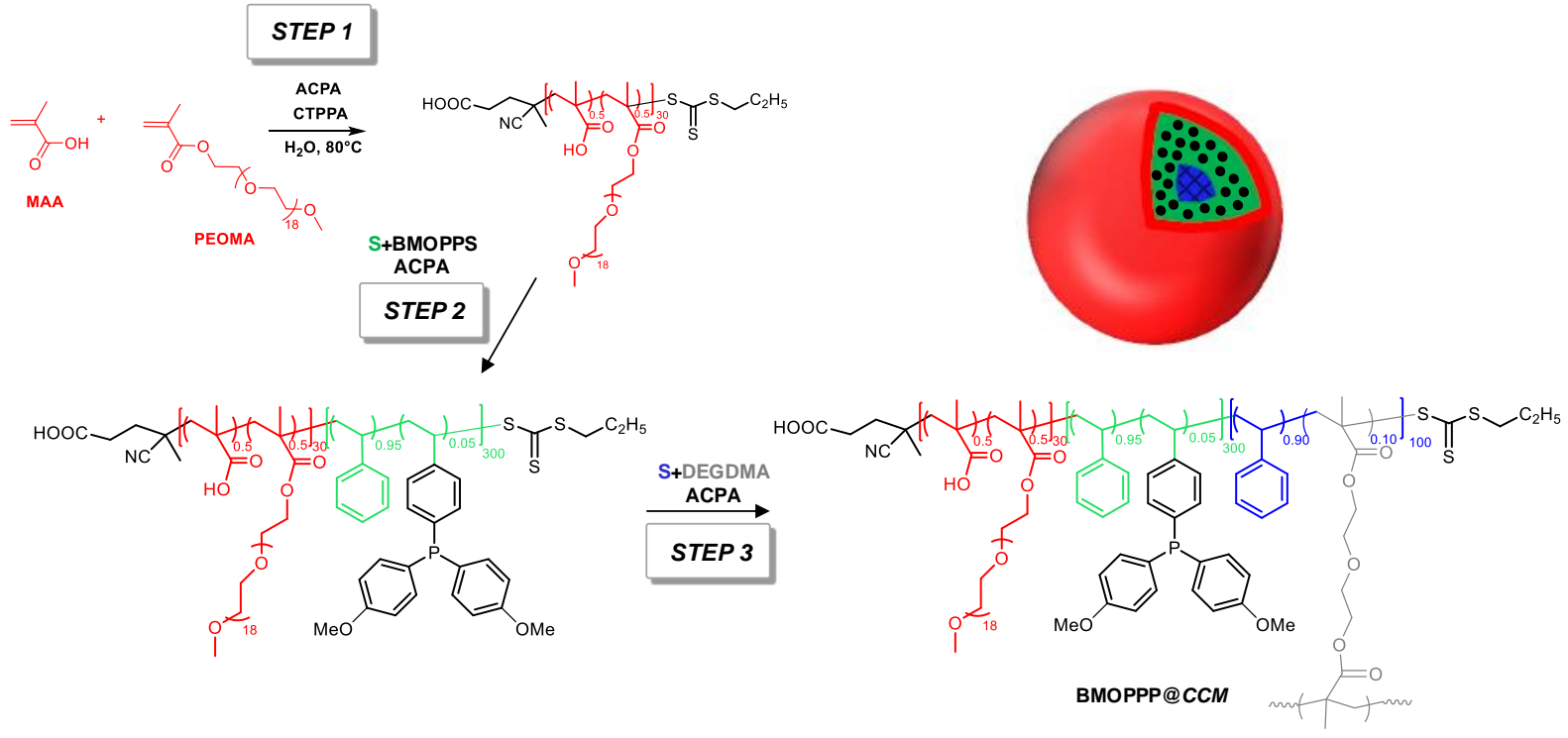


Scheme 2. Synthesis of the BMOPPP@CCM latex.
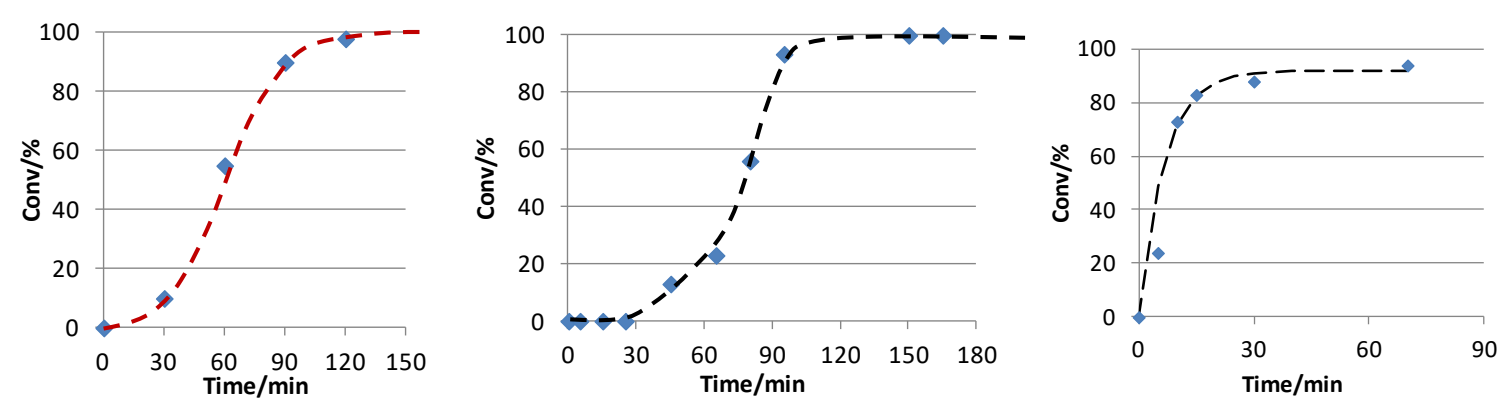

Figure 1. Conversion versus time for the three steps of the BMOPPP@CCM latex synthesis depicted in Scheme 2: step 1 (left), step 2 (center) and step 3 (right).

The resulting water-soluble $\mathrm{HOOCCH}_{2} \mathrm{CH}_{2} \mathrm{C}(\mathrm{CN})\left(\mathrm{CH}_{3}\right)-\mathrm{P}\left(\mathrm{MAA}_{15}-\mathrm{co}\right.$ - $\left.\mathrm{PEOMA}_{15}\right)$ SC(S)SPr was used in step 2 as macro-controlling agent, upon further addition of ACPA, for the chain extension with the mixture of styrene (S) and BMOPPS (95:5 molar ratio corresponding to 300 monomer units per chain). During this step, the solid BMOPPS monomer is dissolved in the styrene yielding a single liquid phase that is added to water. The emulsion polymerization starts rather slowly with an induction period (Figure 1, center) that corresponds

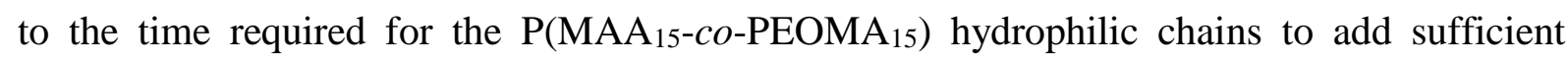
hydrophobic monomer units to start to self-assemble. Once micelles are formed, the polymerization is fast and a complete conversion is obtained within $2 \mathrm{~h}$. The polymer SEC analysis confirms the efficiency and control of the chain extension. The experimentally determined molar mass $\left(M_{\mathrm{n}}=43900 \mathrm{~g} \mathrm{~mol}^{-1}\right)$ of the polymer analyzed after this step increased relative to the starting $\mathrm{P}\left(\mathrm{MAA}_{15}-\right.$ co-PEOMA $\left.{ }_{15}\right)$ chains while the molar mass distribution remained narrow $(\bigoplus=1.3)$ although slightly broader than for $\mathrm{P}\left(\mathrm{MAA}_{15}-c o-\mathrm{PEOMA}_{15}\right)(\bigoplus=$ 1.19). This appears related to the presence of a certain amount of dead $P\left(M_{15} A_{15}-c o-P E O M A_{15}\right)$ chains, see Figure S2 in the Supporting Information. Nevertheless, P(MAA-co-POEMA)- $b$ $\mathrm{P}(\mathrm{S}-\mathrm{co}$-BMOPPP) amphiphilic block copolymer micelles exhibiting narrowly distributed sizes were obtained after step 2 (see characterization below). Using a proportion of the phosphinefunctionalized monomer greater than $5 \%$ results in a three-phase system with undissolved solid BMOPPS and the polymerization does not yield well-dispersed micelles of narrow size distribution. Thus, the chemistry involving BMOPPP is less flexible in terms of degree of ligand functionality relative to the previously reported TPP@CCM synthesis, where the hydrophobic core could be charged with up to $25 \%$ of the phosphine-functionalized monomer DPPS [26, 27]. 
The resulting solution was then treated in a third step with a 90:10 molar mixture of styrene and di(ethylene glycol) dimethacrylate (DEGDMA) used as cross-linking agent. This step takes place very rapidly without induction time (Figure 1, right) to yield the desired BMOPPP@CCM. Higher content of DEGDMA would not induce the formation of individual core-shell nano-objects but rather a macrogel formation, as described previously [26].

\subsection{BMOPPP@CCM characterization}

The full ${ }^{1} \mathrm{H}$ and ${ }^{31} \mathrm{P}\left\{{ }^{1} \mathrm{H}\right\}$ NMR characterization was carried out in THF- $d_{8}$, which is a good solvent for all the polymer constituents. The ${ }^{1} \mathrm{H}$ NMR spectrum, see Figure 2a, clearly shows the core aromatic protons in the $\delta$ 7.5-6.2 region. The shell PEO side chains give rise to a sharp resonance at $\delta 3.63$ (overlapped with one of the two THF- $d_{8}$ residual proton resonances) for the $\mathrm{CH}_{2}$ protons and a smaller resonance at $\delta 3.34$ for the OMe chain end. The backbone aliphatic protons of both core and shell are visible as two broad features at $\delta$ 2.2-1.2. The aromatic protons of the BMOPPP moiety overlap with those of PS. The BMOPPP OMe protons probably give rise to the small resonance at $\delta 3.82$, to the left of the large $\mathrm{PEO} \mathrm{CH}_{2}$ resonance ( $c f$. $\delta 3.83$ for the monomer in $\mathrm{CDCl}_{3}$ ), providing direct evidence for the incorporation of BMOPPS in the CCM. Indeed, this peak is absent in the ${ }^{1} \mathrm{H}$ NMR spectrum of the analogous TPP@CCM, the two spectra being otherwise identical [26]. The extensive resonance overlap hampers the quantitative measurement of the core and shell monomers, however more clear information was obtained from the NMR of the swollen latex (next section). Furthermore, a solid state ${ }^{13} \mathrm{C}\left\{{ }^{1} \mathrm{H}\right\}$ MAS-NMR analysis with quantitative integration reveals the correct area ratio expected for the resonances of the aromatic $\mathrm{C}$ atoms at $\delta 125-130$ and of the PEG C atoms at $\delta 70$ (see SI, Figure S3). Further analyses were performed by ${ }^{31} \mathrm{P}\left\{{ }^{1} \mathrm{H}\right\}$ NMR (Figure 2b), which confirmed the incorporation of the phosphine functionalized styrene monomer in the CCM. The phosphorus resonance of the BMOPPS monomer at $\delta-8.9$ is slightly broadened and shifted to $\delta-11.4$ once incorporated in the polymer structure. This displacement was a convenient probe to monitor the BMOPPS consumption during the polymerization. Additional NMR investigations will be shown below, in reference to the complexation studies. 

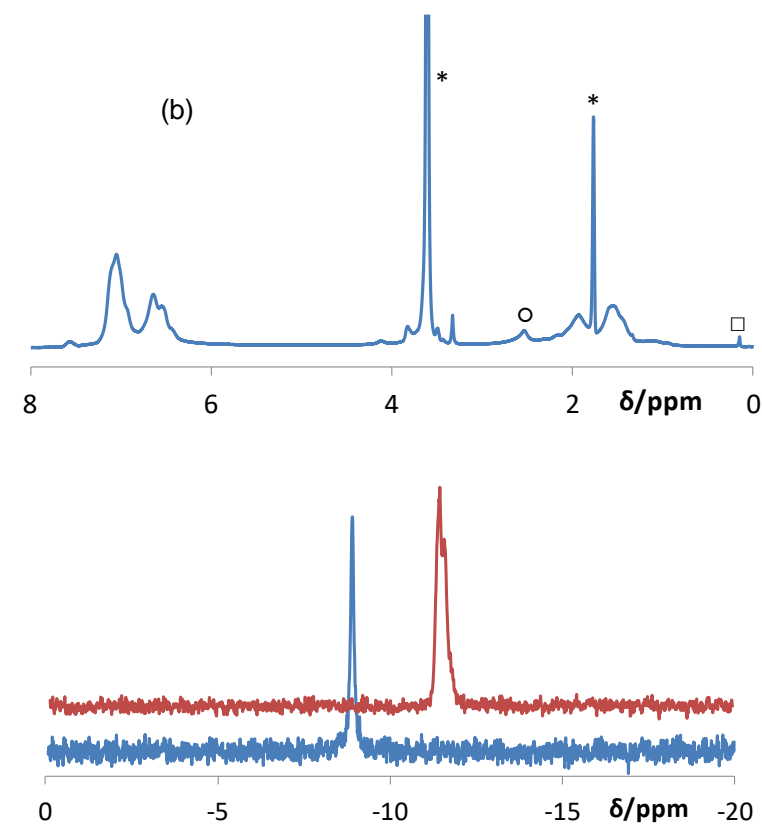

Figure 2. a) ${ }^{1} \mathrm{H}$ NMR spectrum of BMOPPP@CCM in THF- $d_{8}$. The resonance marked with 0 belongs to $\mathrm{H}_{2} \mathrm{O}$, that marked with $\square$ to silicone grease and those marked with $*$ to the THF- $d_{8}$ residual proton resonances. b) ${ }^{31} \mathrm{P}\left\{{ }^{1} \mathrm{H}\right\}$ NMR spectra of the BMOPPS monomer (blue) and of BMOPPP@CCM (brown) in THF- $d_{8}$.

The particle size was measured by DLS in water both before and after cross-linking, as well as in THF for the final cross-linked BMOPPP@CCM particles. The $D_{z}$ values are ca. 80 $\mathrm{nm}$ in water for both the micelles and the CCMs, with a narrow size distribution (PDI ca. 0.2). The CCMs swelled by a factor of ca. 2.5 in diameter (17 in volume) when placed in a THF solution, see Figure S4 in the SI ( $c f .10$ in volume for the related TPP@CCM, both with 5\% and with $10 \%$ molar fraction of phosphine functionalized monomer in the core $[26,27])$. The spherical morphology, dimensions, and narrow polydispersity were in all cases confirmed by TEM observations (Figure 3).
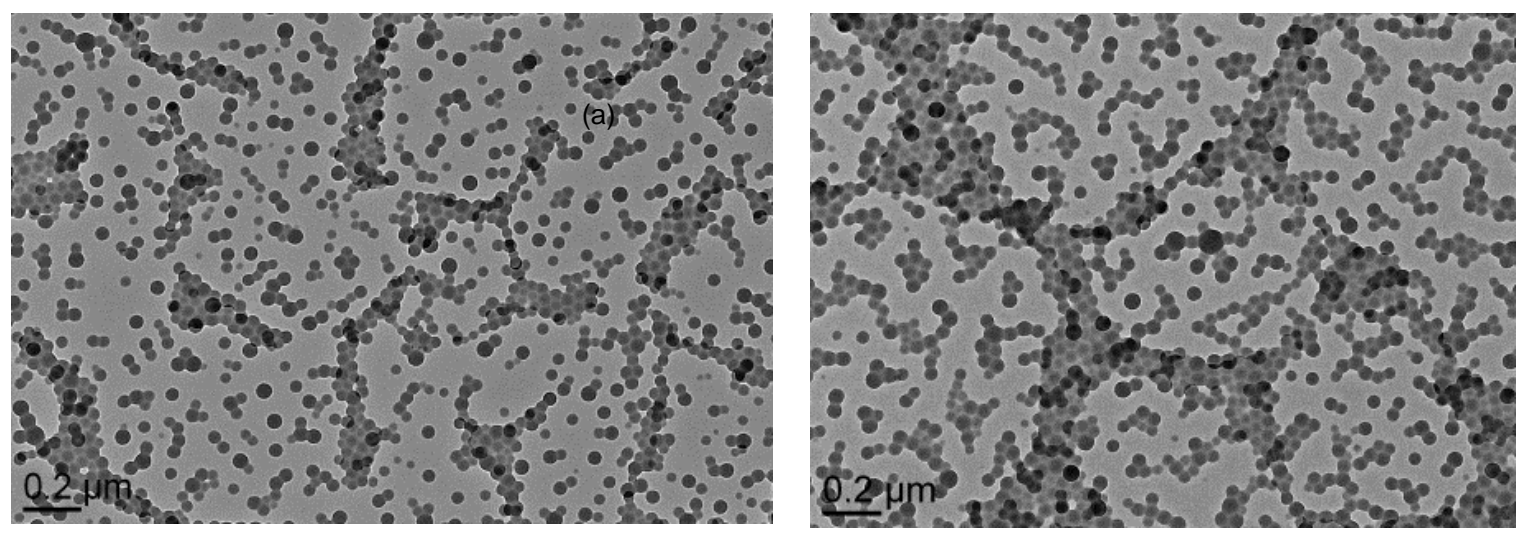

Figure 3. TEM images of micelles (after Step 2 of the synthesis), left, and final core-crosslinked micelles (BMOPPP@CCM), right. 


\subsection{Swelling and metal coordination}

As shown in the previous section, all nano-object flexible components (shell and core linear arms) are well solvated in THF- $d_{8}$. The corresponding ${ }^{1} \mathrm{H}$ NMR spectrum in D-enriched water (obtained upon directly diluting the latex with $\mathrm{D}_{2} \mathrm{O}$, Figure 4(a)) only shows the watersolvated hydrophilic shell: $\mathrm{PEO} \mathrm{CH}_{2}$ resonance at $\delta 3.63$ and small resonance at $\delta 3.32$ for the terminal $\mathrm{OCH}_{3}$ group (better visible in the expansion of Figure 4C). The small and irregular shoulder upfield of the more intense $\mathrm{CH}_{2}$ resonance (at ca. $\delta 3.55$ ) is probably caused by the PEO $\mathrm{CH}_{2}$ groups located close to the shell/core interface. Water is a non-solvent for the polystyrene-based core. The ${ }^{31} \mathrm{P}\left\{{ }^{1} \mathrm{H}\right\}$ spectrum does not show any visible resonance, Figure $5(\mathrm{a})$.
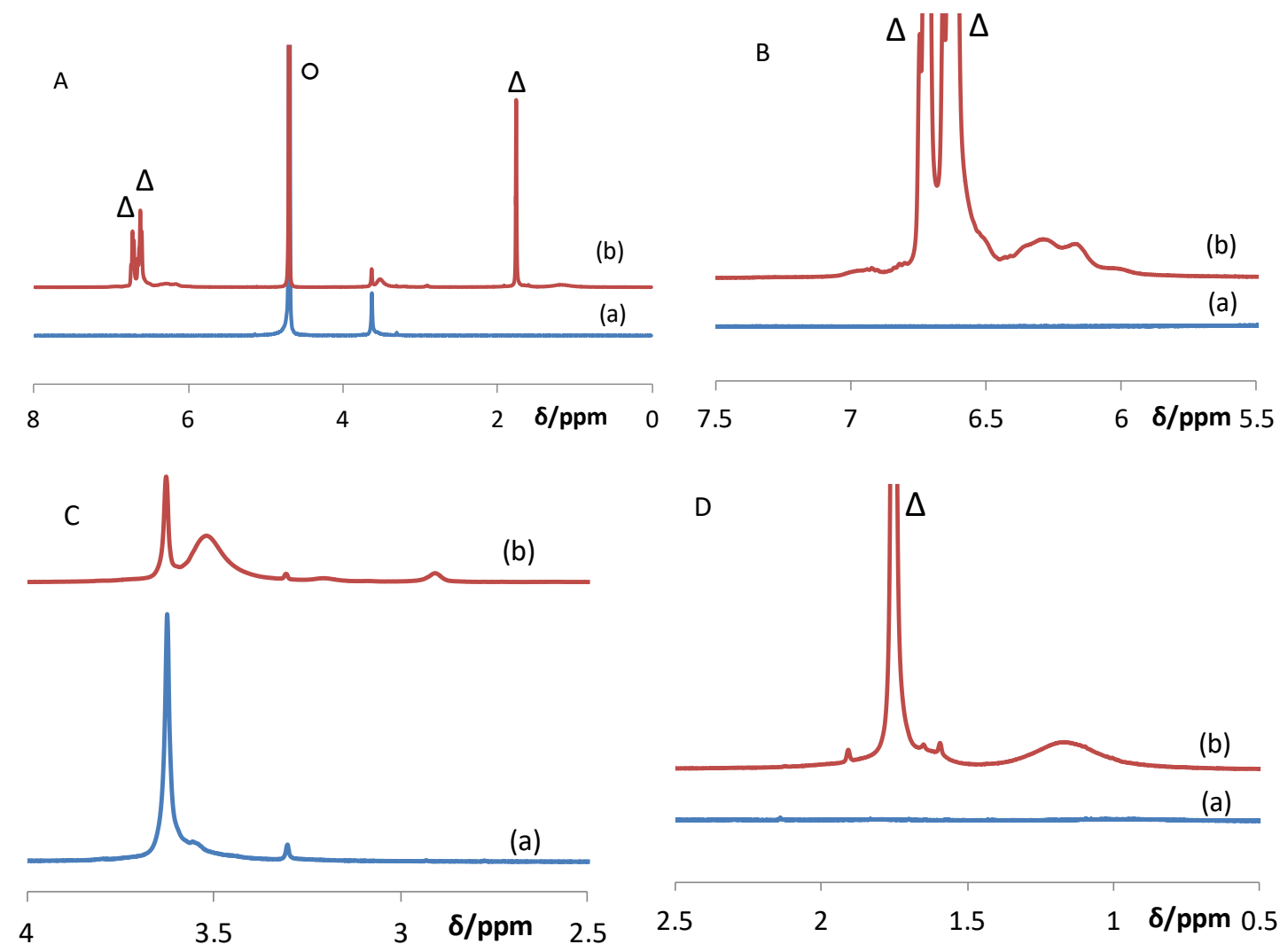

Figure 4. A: ${ }^{1} \mathrm{H}$ NMR spectrum of BMOPPP@CCM in $\mathrm{D}_{2} \mathrm{O}$ before (a) and after (b) swelling with toluene. B-D: Expansions in selected regions. The resonance marked with $\circ$ is due to water, while those marked with $\Delta$ belong to the swelling toluene molecules. 


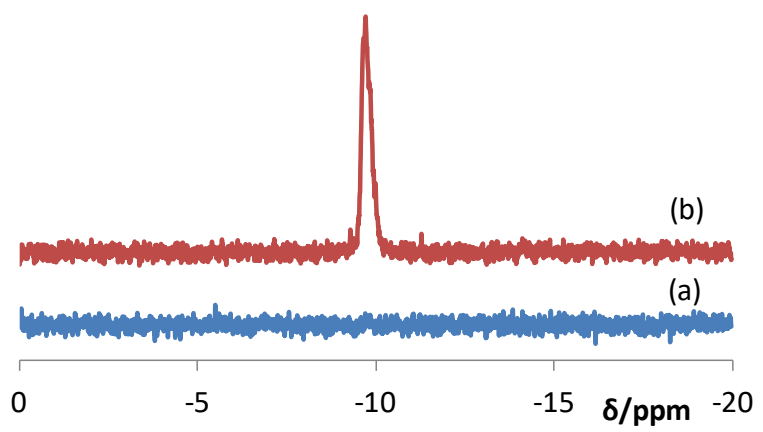

Figure 5. ${ }^{31} \mathrm{P}\left\{{ }^{1} \mathrm{H}\right\}$ NMR spectrum of BMOPPP@CCM in $\mathrm{D}_{2} \mathrm{O}$ before (a) and after (b) swelling with toluene.

Swelling of the CCM latex by toluene leads to several changes in the ${ }^{1} \mathrm{H}$ NMR spectrum, see Figure 4(b). A first one is the reappearance of the core constituents as broad features at $\delta 6$ 7 for the aromatic protons (Figure 4B) and at $\delta 1-2$ for the backbone protons (Figure 4D). These broader resonances overlap with the sharper ones of the free toluene located inside the CCM core (only the latex phase was carefully selected for the NMR measurement after swelling and decanting), at $\delta$ 6.5-6.8 (aromatic) and 1.75 (methyl). The small resonance at $\delta 2.9$ (see Figure 4C) is assigned to the BMOPPP methoxy protons. Although this resonance is upfield shifted by almost $1 \mathrm{ppm}$ from the value in the monomer and in the THF- $d_{8}$-solvated polymer (vide supra), which may be related to the different solvation, there are no other resonances expected for the polymer in this region and the integrated intensity relative to the PEO peaks is in relatively good agreement with the expected value (observed ratio of $0.061 \mathrm{vs}$. a theoretical value of 0.076). For comparison, the OMe resonance in the BMOPPS monomer also shifts upfield from $\delta 3.83$ to 3.27 when the solvent is changed from $\mathrm{CDCl}_{3}$ to toluene- $d_{8}$. Note that no backbone resonance is visible for the unswollen sample, suggesting that only the PEO chains are solvated by water, whereas the polymer chain backbone and the MAA methyl groups of the shell compartment remain solidary with the hydrophobic core in the pristine (unswollen) latex. The core phosphine functions become equally visible, after swelling, by ${ }^{31} \mathrm{P}\left\{{ }^{1} \mathrm{H}\right\}$ NMR with a resonance at $\delta-9.7$, Figure 5(b). A second change caused by swelling in the ${ }^{1} \mathrm{H}$ NMR spectrum is the splitting of the $\mathrm{PEO} \mathrm{CH}_{2}$ and $\mathrm{CH}_{3}$ resonances into a pair of smaller and sharper resonances on one hand, located at the same positions as in the unswollen latex (cf. (a) and (b) in Figure 4C) and therefore assigned to water-solvated PEO chains, and a pair of more intense and broader resonances on the other hand, shifted upfield to $\delta 3.52\left(\mathrm{CH}_{2}\right)$ and $3.20\left(\mathrm{CH}_{3}\right)$. The latter are assigned to PEO chains that are folded back into the swollen core. Hence, the polystyrene 
core solvation by toluene makes this environment compatible with the PEO chains. The deconvolution of the $\mathrm{PEO} \mathrm{CH}_{2}$ resonance as the sum of two Lorentzian functions (see details in the SI, Figure S5) yields a chain distribution of $(23.2 \pm 0.1) \%$ in water and $(76.8 \pm 0.1) \%$ in the core. This illustrates a slightly greater tendency of core confinement for toluene-swollen BMOPPP@CCM than for the analogous TPP@CCM (10\% of triphenylphosphine molar content in the core), for which the water/core ratio was determined by the same technique as 30.3:69.7( \pm 0.1$))[26]$.

Integration of the ${ }^{1} \mathrm{H}$ spectrum for the toluene-swollen sample affords the expected intensities of the aromatic and backbone protons relative to the PEO protons when considering only the protons in the flexible chains (i.e. excluding the cross-linked nucleus, presumably characterized by slow tumbling even after swelling) and also allows a rough estimate of the amount of toluene, although these measurements are quite imprecise because of overlap. The solvent amount is in the range of 730-810 molecules per chain, depending on whether the calculation is based on the Me or the aromatic resonance intensity. This amount is similar to that measured for the swelling of the related TPP@CCM [26].

After swelling, the hydroformylation precatalyst, $\left[\mathrm{Rh}(\mathrm{acac})(\mathrm{CO})_{2}\right]$, could be readily introduced into the CCM core by stirring the latex with a toluene solution of the metal complex, as demonstrated by ${ }^{31} \mathrm{P}\left\{{ }^{1} \mathrm{H}\right\}$ NMR. The reaction leads to replacement of one CO ligand by the polymer-anchored phosphine with formation of $[\mathrm{Rh}(\mathrm{acac})(\mathrm{CO})(\mathrm{BMOPPP} @ \mathrm{CCM})]$, as indicated by the disappearance of the metal-free BMOPPP@CCM resonance at $\delta-11.4$ and its replacement with a doublet at $\delta 44.5\left(\mathrm{~J}_{\mathrm{PRh}}=176 \mathrm{~Hz}\right)$ when one equivalent of $\mathrm{Rh}$ per $\mathrm{P}$ atom is introduced in the CCM, see Figure 6. The analogous molecular complex $[\mathrm{Rh}(\mathrm{acac})(\mathrm{CO})(\mathrm{BMOPPP})]$ has not been reported to the best of our knowledge, but the resonances of related complexes $[\mathrm{Rh}(\mathrm{acac})(\mathrm{CO})(\mathrm{TPP})]$ and $[\mathrm{Rh}(\mathrm{acac})(\mathrm{CO})(\mathrm{TMOPP})][\mathrm{TMOPP}$ $=$ tris $\left(4-\right.$-methoxyphenyl)phosphine], which are reported respectively at $\delta 48.6\left(\mathrm{~J}_{\mathrm{PRh}}=179.7 \mathrm{~Hz}\right)$ [35] and $43.5\left(\mathrm{~J}_{\mathrm{PRh}}=175.6 \mathrm{~Hz}\right)$ [36], bracket the resonance attributed to [Rh(acac)(CO)(BMOPPP@CCM)]. When only half of the phosphine ligands are metal bonded $(\mathrm{Rh} / \mathrm{P}=0.5)$, however, no signal is visible in the ${ }^{31} \mathrm{P}\left\{{ }^{1} \mathrm{H}\right\}$ NMR spectrum. This behavior is identical to that observed for the analogous $[\mathrm{Rh}(\mathrm{acac})(\mathrm{CO})(\mathrm{TPP} @ \mathrm{CCM})]$ and is assigned to a rapid exchange between the coordinated and the free phosphine ligands [26]. This observation indicates that the exchange rate for the BMOPP ligand, like that of the TPP ligand, is in the appropriate range to yield coalescence at room temperature. 


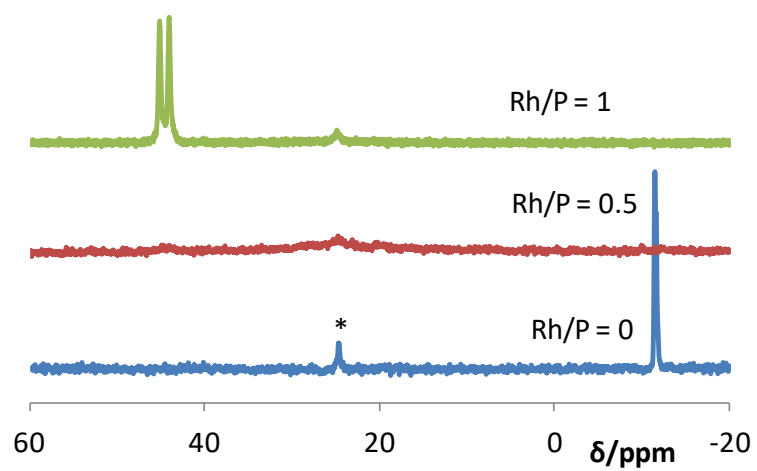

Figure 6. ${ }^{31} \mathrm{P}\left\{{ }^{1} \mathrm{H}\right\}$ NMR spectra of $[\mathrm{Rh}(\mathrm{acac})(\mathrm{CO})(\mathrm{BMOPPP} @ \mathrm{CCM})]$ with different amounts of rhodium complex. The starred resonance is due to a minor amount of oxidized phosphine impurity.

\subsection{Hydroformylation catalysis}

The BMOPPP@CCM latex was investigated as nanoreactor for the biphasic Rh-catalyzed hydroformylation of 1-octene, using the same operating conditions as for the related TPP@CCM [26, 27]: 363 K, 20 bar of syngas pressure and 20\% molar as initial concentration of 1-octene in decanal. The volume ratio of organic mixture to aqueous latex suspension was set to 3:1 to keep the catalytic phase dispersed into the organic phase after swelling of the CCM. Table 1 compares the performance of this new ligand in terms of activity, selectivity and Rh leaching with respect to the reference TPP@CCM. As stated in section 3.1, the BMOPPP@CCM latex could only be prepared with a molar fraction of functionalized monomer in the hydrophobic core of 5\% (BMOPPS:S = 1:19), whereas the corresponding TPP@CCM latex could also be prepared with higher molar fractions [26]. The most useful comparison in terms of performances related the two CCM with the same functional monomer content [27]. The BMOPPP@CCM based catalyst yielded a quite similar performance as the TPP homologue, with a marginally greater initial TOF and a marginally smaller $1 / b$ ratio. Similar activities and selectivities were also reported in homogeneous catalysis in the presence of $p$ OMe-substituted and non-substituted arylphosphines [30, 31]. However, the BMOPPP@CCM based catalyst unexpectedly resulted in twice more rhodium leaching in the organic phase. This leaching does not appear related to loss of rhodium from the nanoreactors. Indeed, it is known that $\mathrm{Rh}^{\mathrm{I}}$ binds more strongly to $\mathrm{P}\left(\mathrm{C}_{6} \mathrm{H}_{4}-p-\mathrm{OMe}\right)_{3}$ than to $\mathrm{P}\left(\mathrm{C}_{6} \mathrm{H}_{5}\right)_{3}$ by $7.0 \mathrm{kcal} / \mathrm{mol}$ [32]. Furthermore, we have previously demonstrated by DLS analysis that the recovered organic phase contains significant amounts of nano-objects and that the affinity of the nanoreactors for the organic phase increases with core swelling and aggregation [27]. 
Table 1. Results of the biphasic hydroformylation of 1-octene. ${ }^{a}$

\begin{tabular}{|c|c|c|c|c|c|}
\hline Entry & Investigated ligand & $\underset{\left(\mathrm{kmol} \cdot \mathrm{m}_{\text {甲aq }}^{-3} \cdot \mathrm{s}^{-1}\right)}{\text { Initial rate }^{b}}$ & $\begin{array}{c}\mathbf{T O F}_{\text {max }} b \\
\left(\mathrm{~h}^{-1}\right)\end{array}$ & $\begin{array}{c}1 / b^{c} \\
(-)\end{array}$ & $\begin{array}{c}\text { Leaching }^{d} \\
{[\mathrm{Rh}]_{\varphi o r g}(\mathrm{ppm})}\end{array}$ \\
\hline 1 & $\begin{array}{c}\text { BMOPPP@CCM } \\
\text { (BMOPPS:S = 1:19) }\end{array}$ & $1.3 \cdot 10^{-3}$ & 742 & 2.7 & 4.5 \\
\hline $2^{e}$ & $\begin{array}{l}\text { TPP@CCM with } \\
\text { (DPPS:S = 1:19) }\end{array}$ & $1.3 \cdot 10^{-3}$ & 695 & 3.3 & 1.8 \\
\hline
\end{tabular}

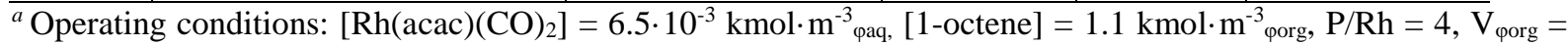
$75 \mathrm{~mL}$ (octene + decanal), $\mathrm{V}_{\text {甲aq }}=25 \mathrm{~mL}$ (latex + water), $\mathrm{T}=363 \mathrm{~K}, \mathrm{P}_{\text {syngas }}=20 \mathrm{bar}\left(\mathrm{CO} / \mathrm{H}_{2}=1\right), \omega=1200 \mathrm{rpm}$. ${ }^{b}$ Initial reaction rate (with respect to non-swollen aqueous phase) and corresponding TurnOver Frequency calculated from the syngas consumption during the first $5 \mathrm{~min}$ of reaction after the gas absorption phase ${ }^{c}$ Linear to branched aldehyde ratio determined from the GC/FID analysis of the final sample. ${ }^{d} \mathrm{Rh}$ concentration in the organic phase measured by ICP/MS. ${ }^{e}$ Results recalled from ref. [27].
}

The DLS measurement of the organic phase recovered after run 1 (Table 1) yields the result shown in Figure 7. The measurement confirms that there are indeed particles dispersed in the organic phase and that these belong to two separate distributions. A minor distribution with average $D_{z}=120 \mathrm{~nm}$ corresponds to the expected size for the CCM after swelling with the solvent of the catalytic run (decanal, a poorer solvent than THF for the polymer core). The major distribution has a much larger average particle size (average $D_{z}=950 \mathrm{~nm}$ ), clearly corresponding to aggregated polymer particles. The much greater size of this distribution and its greater proportion relative to the non-aggregated distribution, with respect to the particles found in the organic phase after catalysis with [Rh(acac)(CO)(TPP@CCM)] [27], gives additional weight to our recent proposition that bigger aggregates become more lipophilic and therefore leaching correlates with the extent of aggregation. Further proof of the presence of nanoparticles in the organic phase is provided by ${ }^{31} \mathrm{P}$ NMR (see SI, Figure S6).

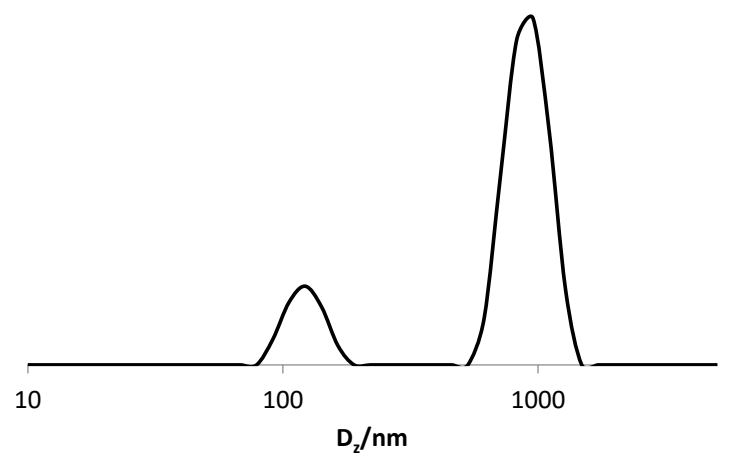

Figure 7. DLS of the recovered organic phase from the catalytic run (entry 1, Table 1). 
The reason for the formation of bigger aggregates with BMOPPP than with TPP can be attributed to the greater affinity of BMOPPP for binding $\mathrm{Rh}$ [32]. Since the experiments are run with a high $\mathrm{P}: \mathrm{Rh}$ ratio in order to have optimum $1 / \mathrm{b}$ selectivity and since the catalyst exists as equilibrating $\left[\mathrm{RhH}(\mathrm{CO})_{3}\right.$ (phosphine) $]$ and $\left[\mathrm{RhH}(\mathrm{CO})_{2}(\text { phosphine })_{2}\right]$ species, a greater proportion of the bis-phosphine species will be generated by the better binding BMOPPP, which leads to the greater formation of lipophilic aggregates by interparticle cross-linking. We have not carried out specific recycling experiments for this particular catalytic nanoreactor, since such studies were previously carried out for the related TPP@CCM, which shows lower leaching.

\section{Conclusions}

Replacement of diphenylphosphinostyrene with 4-[bis( $p$-methoxyphenyl)phosphino]styrene in our optimized synthesis of core-cross-linked micelles (CCM) by emulsion RAFT polymerization [26, 27] leads to the successful fabrication of functionalized nanoreactors containing covalently linked bis(p-methoxyphenyl)phenylphosphine (BMOPPP) ligands in the hydrophobic core, although incorporation of this ligand functionalized monomer is limited by its low solubility in styrene. These BMOPPP@CCM nanoreactors show the same behavior as the previously described TPP@CCM in terms of core swelling, coordination of $\left[\mathrm{Rh}(\mathrm{acac})(\mathrm{CO})_{2}\right]$, intra-particle phosphine ligand exchange, and catalytic activity in aqueous biphasic 1-octene hydroformylation. Catalyst leaching, however, is slightly greater, proving the point that this metal leaching process is not related to partial metal loss from the nanoreactor but rather to partial loss of the entire nanoreactor into the organic product phase. This phenomenon is presumably favored by a greater tendency of this more strongly bonding phosphine to form bigger and more lipophilic particle aggregates through interparticle crosslinking. On the basis of these hypotheses, improvement of this catalytic nanoreactor appears possible by turning to polymer-anchored bidentate ligands and efforts to assemble polymer architectures of this type are currently underway.

\section{Acknowledgements}


We are grateful to the Agence Nationale de la Recherche (ANR) for support of this work through grant "BIPHASNANOCAT" (ANR-11-BS07-025-01). Additional support from the Centre National de la Recherche Scientifique (CNRS) and from the Institut Universitaire de France (IUF) is also gratefully acknowledged.

\section{Appendix A. Supplementary data}

Supplementary data related to this article can be found at http://dx.doi.org/10.1016/j.polymer.xxxxx.

\section{References}

1. Matyjaszewski K, Gnanou Y, and Leibler L. Macromolecular Engineering: Precise Synthesis, Materials Properties, Applications: Wiley-VCH Verlag GmbH, 2007.

2. Welsch N, Ballauff M, and Lu Y. Adv. Polym. Sci. 2010;234:129-163.

3. $\quad$ Lu A and O'Reilly RK. Curr. Opin. Biotech. 2013;24(4):639-645.

4. Terashima T. Polymer Microgels for Catalysis. In: Mark HF, editor. Encyclopedia of Polymer Science and Technology, 4th Edition: John Wiley \& Sons, Inc., 2013. pp. 10.1002/0471440264.pst0471440590.

5. Chi YG, Scroggins ST, and Fréchet JMJ. J. Am. Chem. Soc. 2008;130(20):6322-6323.

6. Levins AD, Wang XF, Moughton AO, Skey J, and O'Reilly RK. Macromolecules 2008;41(9):2998-3006.

7. Terashima T, Ouchi M, Ando T, and Sawamoto M. J. Polym. Sci., Polym. Chem. 2010;48(2):373-379.

8. Terashima T, Ouchi M, Ando T, and Sawamoto M. Polym. J. 2011;43(9):770-777.

9. Resmini M. Anal. Bioanal. Chem. 2012;402(10):3021-3026.

10. Resmini M, Flavin K, and Carboni D. Mol. Impr. 2012;325:307-342.

11. Cornils B. Org. Process Res. Dev. 1998;2(2):121-127.

12. Kohlpaintner CW, Fischer RW, and Cornils B. Appl. Catal., A 2001;221(1-2):219225.

13. Oehme G. Appl. Homogeneous Catal. Organomet. Compd. (2nd Ed.) 2002;2:835-841.

14. Nuyken O, Weberskirch R, Kotre T, Schoenfelder D, and Woerndle A. Polym. Mater. Org. Synth. Catal. 2003:277-304.

15. Reinsborough VC. Interfacial Catal. 2003:377-390.

16. Kotre T, Zarka MT, Krause JO, Buchmeiser MR, Weberskirch R, and Nuyken O. Macromol. Symp. 2004;217(Contributions from 6th Austrian Polymer Meeting, 2003):203-214.

17. Khan MN. Micellar Catalysis: CRC Press, 2006.

18. Zhang J, Meng XG, Zeng XC, and Yu XQ. Coord. Chem. Rev. 2009;253(1718):2166-2177.

19. Chen H, Li YZ, Chen JR, Cheng PM, He YE, and Li HJ. J. Mol. Catal. A 1999;149(12):1-6.

20. Yang C, Bi XY, and Mao ZS. J. Mol. Catal. A 2002;187(1):35-46.

21. Li M, Li YZ, Chen H, He YE, and Li XJ. J. Mol. Catal. A 2003;194(1-2):13-17. 
22. Liu X, Kong F, Zheng X, and Jin Z. Catal. Commun. 2003;4(3):129-133.

23. Desset SL, Cole-Hamilton DJ, and Foster DF. Chem. Commun. 2007(19):1933-1935.

24. Zarka MT, Bortenschlager M, Wurst K, Nuyken O, and Weberskirch R. Organometallics 2004;23(21):4817-4820.

25. Pawar GM, Weckesser J, Blechert S, and Buchmeiser MR. Beilstein J. Org. Chem. 2010;6:No. 28.

26. Zhang X, Cardozo AF, Chen S, Zhang W, Julcour C, Lansalot M, Blanco J-F, Gayet F, Delmas H, Charleux B, Manoury E, D'Agosto F, and Poli R. Chem. Eur. J. 2014;20(47):15505-15517.

27. Cardozo AF, Julcour C, Barthe L, Blanco J-F, Chen S, Gayet F, Manoury E, Zhang X, Lansalot M, Charleux B, D'Agosto F, Poli R, and Delmas H. J. Catal. in press:DOI: 10.1016/j.jcat.2015.1001.1009.

28. Charleux B, Delaittre G, Rieger J, and D'Agosto F. Macromolecules 2012;45(17):6753-6765.

29. Warren NJ and Armes SP. J. Am. Chem. Soc. 2014;136(29):10174-10185.

30. Barros HJV, Ospina ML, Arguello E, Rocha WR, Gusevskaya EV, and dos Santos EN. J. Organomet. Chem. 2003;671(1-2):150-157.

31. Wang X, Fu HY, Li XJ, and Chen H. Catal. Commun. 2004;5(12):739-741.

32. Serron S, Nolan SP, and Moloy KG. Organometallics 1996;15:4301-4306.

33. Boursier T, Chaduc I, Rieger J, D'Agosto F, Lansalot M, and Charleux B. Polym. Chem. 2011;2(2):355-362.

34. Choi MKW, He HS, and Toy PH. J. Org. Chem. 2003;68(25):9831-9834.

35. Bonati F and Wilkinson G. J. Chem. Soc. 1964(SEP):3156-3160.

36. Pruchnik FP, Smolenski P, and Wajda-Hermanowicz K. J. Organomet. Chem. 1998;570(1):63-69. 